\title{
Modelling estuarine wetlands under climate change and infrastructure pressure
}

\author{
$\underline{\text { F.N. Trivisonno }}^{1}$, J.F. Rodríguez ${ }^{1}$, G.A. Riccardi ${ }^{2}$, P.M. Saco ${ }^{1}$ and H. Stenta ${ }^{2}$ \\ ${ }^{1}$ School of Engineering, The University of Newcastle, University Drive, Callaghan, NSW 2308, Australia \\ ${ }^{2}$ Departamento de Hidráulica and CURIHAM, Facultad de Ciencias Exactas, Ingeniería y Agrimensura, \\ Universidad Nacional de Rosario, Riobamba 245 bis (2000) Rosario, Argentina \\ Email: Franco.Trivisonno@uon.edu.au
}

\begin{abstract}
Estuarine wetlands are an extremely valuable resource in terms of biotic diversity, flood attenuation, storm surge protection, groundwater recharge, filtering of surface flows and carbon sequestration. The survival of these systems depends on a balance between the slope of the land, and the rates of accretion and sea-level rise. Climate change predictions for most of Australia include both an accelerated sea-level rise and an increase on the frequency of extraordinary river floods, which will endanger estuarine wetlands. Furthermore, coastal infrastructure poses an additional constraint on the adaptive capacity of these ecosystems. In recent years a number of numerical models have been developed in order to assess wetland dynamics and to help manage some of these situations.
\end{abstract}

In this paper we present a wetland evolution model that is based on computed values of hydroperiod and tidal range that drive vegetation preference. Results from a 2D spatially distributed model of wetland dynamics in area E of Kooragang Island (Hunter estuary, NSW) are presented as an example of a system heavily constricted by infrastructure undergoing the effects of sea level rise. Area E presents a vegetation zonation sequence mudflats - mangrove - saltmarsh from the seaward margin and up to the topographic gradient and is compartmentalized by the presence of internal culverts. The model includes a detailed hydrodynamic module (CTSS8), which is able to handle man-made flow controls and spatially varying roughness. The model continually simulates tidal inputs into the wetland and computes annual values of hydroperiod and tidal range to update vegetation distribution based on preference to hydrodynamic conditions of the different vegetation types. It also computes soil accretion and carbon sequestration rates and updates roughness coefficient values according to evolving vegetation types.

In order to further explore the magnitude of flow attenuation due to roughness and its effects on the computation of tidal range and hydroperiod, numerical experiments were carried out simulating floodplain flow on the side of a tidal creek using different roughness values. Even though the values of roughness that produce appreciable changes in hydroperiod and tidal range are relatively high, they are within the range expected for some of the wetland vegetation.

Both applications of the model show that flow attenuation plays a major role in wetland hydrodynamics and that its effects must be considered when predicting wetland evolution under climate change scenarios, particularly in situations where existing infrastructure affects the flow.

Keywords: Vegetation dynamics, estuarine wetlands, sea-level rise 


\section{INTRODUCTION}

Vegetation species present in estuarine wetlands often constitute unique habitats for a particular biota. Predicted changes in environmental conditions over the next century include an accelerated sea-level rise and an increase on the frequency of extraordinary river floods for most of Australia, both of which will pose a threat to estuarine wetlands, and mainly the ones comprising mangroves and saltmarsh. In the Hunter estuary of NSW, as in most of south eastern Australia, estuarine wetlands typically comprise intertidal mudflats at the seaward margin, followed further inland first by mangrove forest and then by saltmarsh plains. Mangrove forest and saltmarsh are important for estuarine fish [Mazumder et al., 2005] and provide unique habitats for terrestrial fauna. In particular, saltmarsh is used by insectivorous bats as feeding habitat and by shorebirds as roosting habitat, clearly preferring it to mangrove forest [Saintilan and Rogers, 2006].

Estuarine wetlands are sinks for fine grained riverine sediment and, during periods of sea-level rise, tend to maintain their relative submergence mainly through the mechanism of accretion (surface build-up via sedimentation). Therefore, they are able to sequester carbon at higher rates than forests [Howe et al., 2009; Mitsch et al., 2012]. Since this carbon is buried, the sequestration is essentially permanent. This has prompted international initiatives to develop wetland "blue carbon" offset standards and projects certifiable by the Clean Development Mechanism or the Voluntary Carbon Standard in a similar fashion to the most traditional forest or renewable energy offsets [Danone Fund for Nature, 2010].

Being these wetlands, from a sedimentary point of view, depositional environments, their survival depends on a delicate balance between the slope of the land, the rate of accretion and the rate of sea level rise. Therefore it is the complex interaction between hydrology, ecology and soil processes that produce positive feedbacks and self-organization of the system, which typically takes the form of a zonation of the vegetation communities [Saco and Rodríguez, 2013]. As complex systems, wetlands can show resilience under a wide range of conditions but also have thresholds above which they can collapse or move to another equilibrium state.

In this paper we present two applications of a physically-based model that incorporates a variety of physical and biological processes and can thus be potentially used in different wetland systems. Tidal range and hydroperiod are the hydraulic variables thought to control vegetation spatial distribution. Since accurate computation of these variables require detailed time-consuming simulations, typical wetland evolution models use instead local values of depth below mean sea level. While this simplification is acceptable in cases where flow attenuation is negligible, high roughness (typical of wetland vegetation) or man-made flow controls (i.e. culverts and weirs) generate changes in the hydrographs that need to be taken into account.

The proposed model puts together state of the art techniques in numerical modelling using high resolution data provided by measurement and monitoring of wetlands. Its use is adequate in medium time-scales evaluation (10-100 years). The 2D spatially distributed model includes hydrodynamics (using the tool VMMHH 1.0), biomass and sediment transport modules and it is able to include man-made flow controls like culverts and weirs. We analyse two cases in which flow attenuation is important and thus requires full hydrodynamic simulation of hydroperiod and tidal range: 1) effects of man-made flow controls in wetlands in the Hunter estuary (NSW), 2) effects of roughness due to vegetation on the tidal platform on the side of a tidal creek.

\section{WETLAND DYNAMICS ON AREA E OF KOORAGANG ISLAND (NSW)}

A simulation of the distribution of vegetation species was carried out on a rehabilitated wetland in the Hunter estuary, NSW (Australia), the Area E of Kooragang Island (Figure 1) [Trivisonno et al., 2013]. As a result of the infrastructure pressure, the site is bounded by pipelines and railways and divided into different compartments by means of a number of roads that cross through the wetland. Being the internal flow in estuarine wetlands naturally complex, the presence of culverts within this area (derived from drainage management and recent wetland rehabilitation activity) increases the difficulty of hydraulically modelling it. Estuarine habitats observed in the area mainly consist on mangrove forest, saltmarsh, mudflat, tidal pools and tidal creeks, all of them fringed upland by pasture and freshwater/brackish wetlands.

The wetland evolution model used here consists of three modules that simulate interactions among flowvegetation-soil processes over significant time scales. First, an accurate hydrodynamic description of flow is provided by VMMHH 1.0 [Riccardi et al., 2009], a tool resulted from the combination between the hydrologic hydraulic model CTSS8 [Riccardi, 2000; Stenta et al., 2008] and the windows-based platform SIMULACIONES 2.0 [Stenta et al., 2005] for pre and post-processing and visualization of data and results. Results from the hydrodynamic model are integrated over a one-year period and this information is passed on 
to the vegetation module. For the present simulations the computational time-step was set at 5 seconds, while the output time-step was set at 1 hour. CPU time for the simulated period was approximately 10 hours on a Quad.i7-3770 3.40 GHz processor, representing a computing-simulation time ratio greater than 700 . Vegetation in estuarine wetlands responds to hydrodynamic forcing via the hydroperiod (proportion of submergence time) and prevailing tidal range conditions over longer time scales, so a time step of one year is appropriate for modelling [Saco and Rodriguez, 2013]. In order to simulate saltmarsh and mangrove establishment, vegetation-specific preference values of hydroperiod $(H)$ and tidal range $\left(R_{t}\right)$ from field measurements are used. Preference values of $H$ and $R_{t}$ have been experimentally determined for the Hunter wetlands during spring tides [Howe et al., 2010; Rodríguez and Howe, in press]. Finally, soil accretion and surface elevation change (based on experimentally-determined vegetation specific values) were computed.

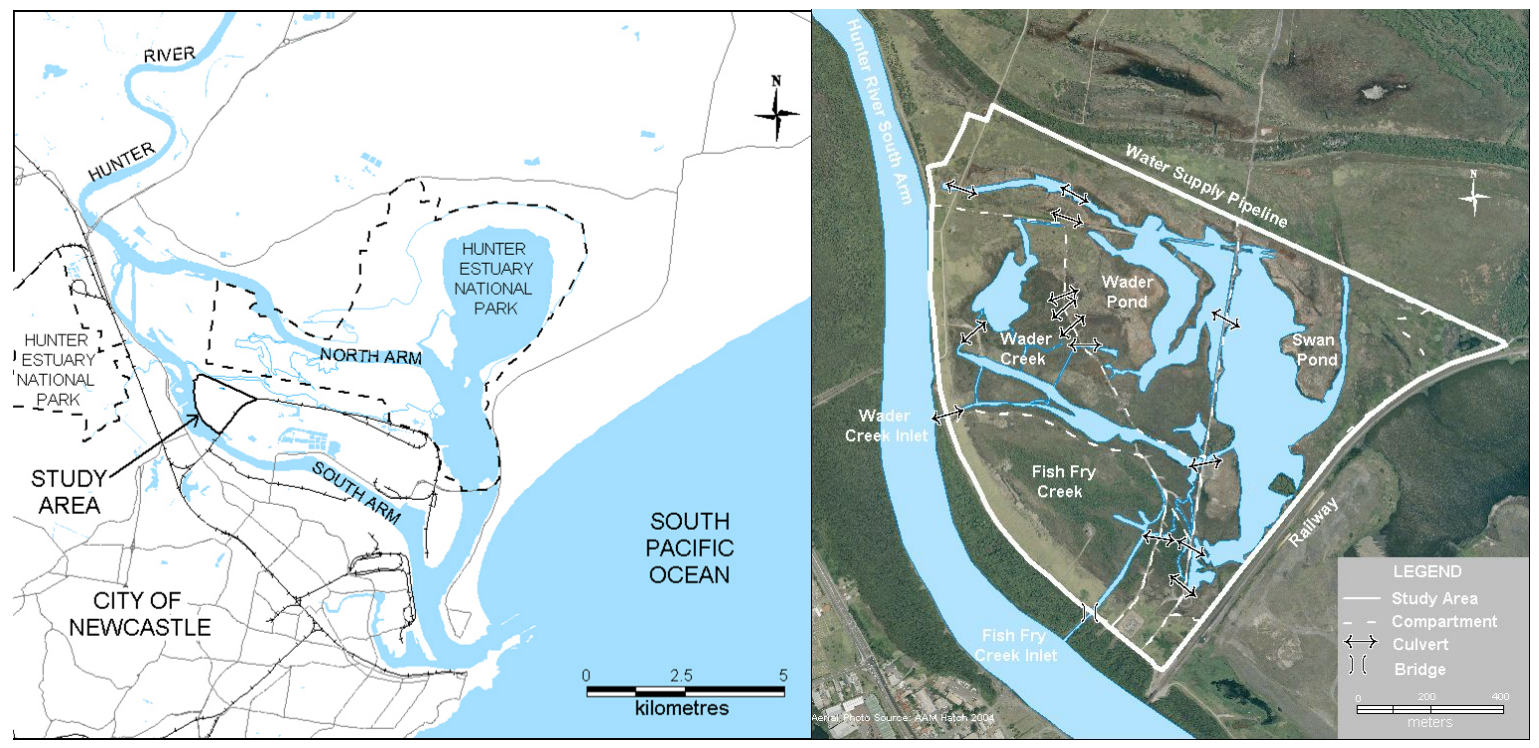

Figure 1. The Hunter estuary (left) and a detail of the Area E of Kooragang Island (right).

Results show that the pair of spatially distributed hydraulic variables hydroperiod $(H)$ and tidal range $\left(R_{t}\right)$ is capable to describe wetland dynamics, even with the inclusion of the main system of culverts -and thus taking into account the effects of these man-made flow controls on temporal flow levels, generating flow attenuation. In Figure 2 it can be seen that observed vegetation zonation (2a) approximately matches model outcomes (2b). The simulated vegetation distribution is in reasonably good agreement with the observed distribution. Simulations of vegetation distribution after 20 years for sea level rise scenarios of $8 \mathrm{~mm} / \mathrm{y}$ and $11 \mathrm{~mm} / \mathrm{y}$ are presented in $(2 \mathrm{c})$ and $(2 \mathrm{~d})$, respectively.

The hydrodynamic simulation showed a remarkable tidal attenuation on certain compartments on the upper wetland area. Tidal attenuation was the result of infrastructure and terrain elevation, and the model results agree with previous measurements [Trivisonno et al., in press].

Evolution of vegetation distribution outputs given by model runs confirms the expected response of estuarine wetlands to sea-level rise: saltmarsh areas migrate inland in order to maintain a favourable position in the tidal frame, but in parts of the wetlands buffer areas for landward migration are not available and saltmarshvegetated area is replaced by tidal pool/mudflat. Using the two different sea-level rise rate scenarios of $8 \mathrm{~mm} \mathrm{y}^{-1}$ and $11 \mathrm{~mm} \mathrm{y}^{-1}$ vegetated area losses ranged from $6.33 \%$ to $13.77 \%$ for mangrove and from $47.04 \%$ to $54.45 \%$ for saltmarsh, respectively. This resulted in a significant reduction of the carbon sequestration rate of the wetland. The reduction is $36.60 \%$ for the lower sea level rise scenario and $44.01 \%$ for the higher sea level rise scenario [Trivisonno et al., in press]. 

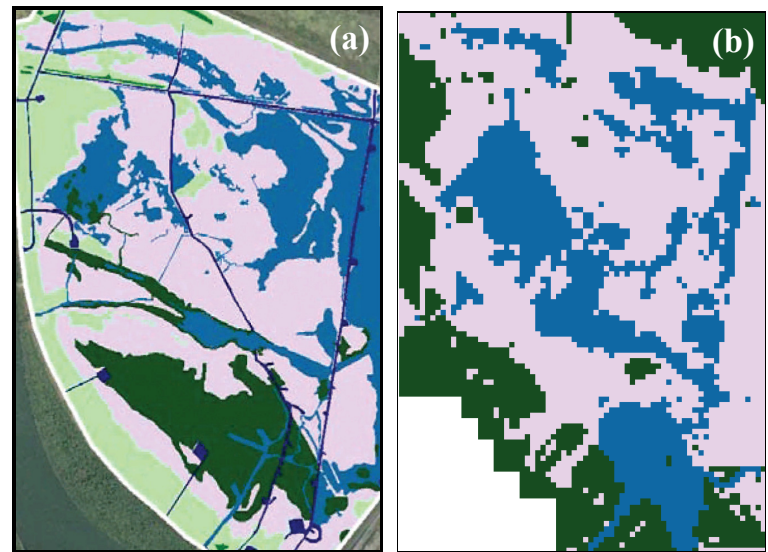

Saltmarsh

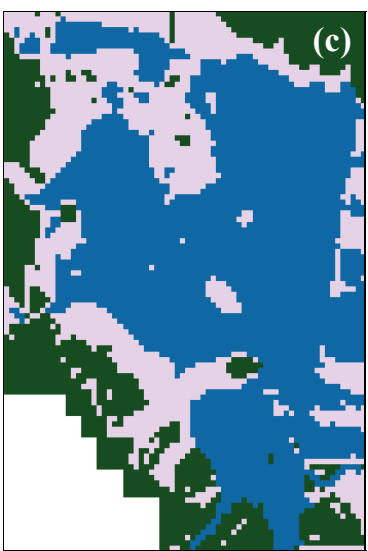

Tidal pool/mudflat

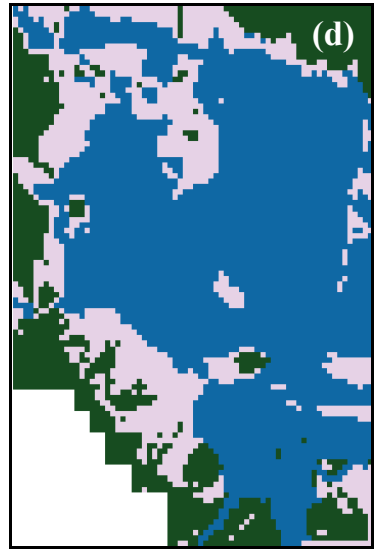

Mangrove

Figure 2. Actual vegetation distribution (a) and simulated vegetation distribution for current tidal and sea level conditions (b); simulated vegetation distribution corresponding to a sea-level rise rate of $8 \mathrm{~mm} \mathrm{y}^{-1}$ (c) and $11 \mathrm{~mm} \mathrm{y}^{-1}(\mathrm{~d})$ over 20-years.

\section{HYDRODYNAMIC EFFECTS OF FLOW ATTENUATION ON WETLANDS}

Estuarine wetlands can be synthesized as a network of channels (or creeks) within a tidal platform, where vegetation growth is observed over the sides of the tidal creeks. In this section we present numerical experiments carried out simulating floodplain flow on the side of a tidal creek, with the aid of the tool VMMHH 1.0 [Riccardi et al., 2009].

As a tidal flow input for the tidal creek we selected a sinusoidal tide with a 12-hours period and a range of $1 \mathrm{~m}$. We studied the ideal case where the mean sea level (MSL) coincides with the top of the stream bank of the tidal creek at an elevation of $0 \mathrm{~m}$. The slope of the tidal platform away from the creek was set at constant value of $0.001 \mathrm{~m} / \mathrm{m}$, which is representative of the wetlands in the Hunter estuary (Figure 3). A number of simulations were conducted for different values of Manning's flow resistance coefficient $(n)$ from 0.1 to 1.0 in 0.1 steps.

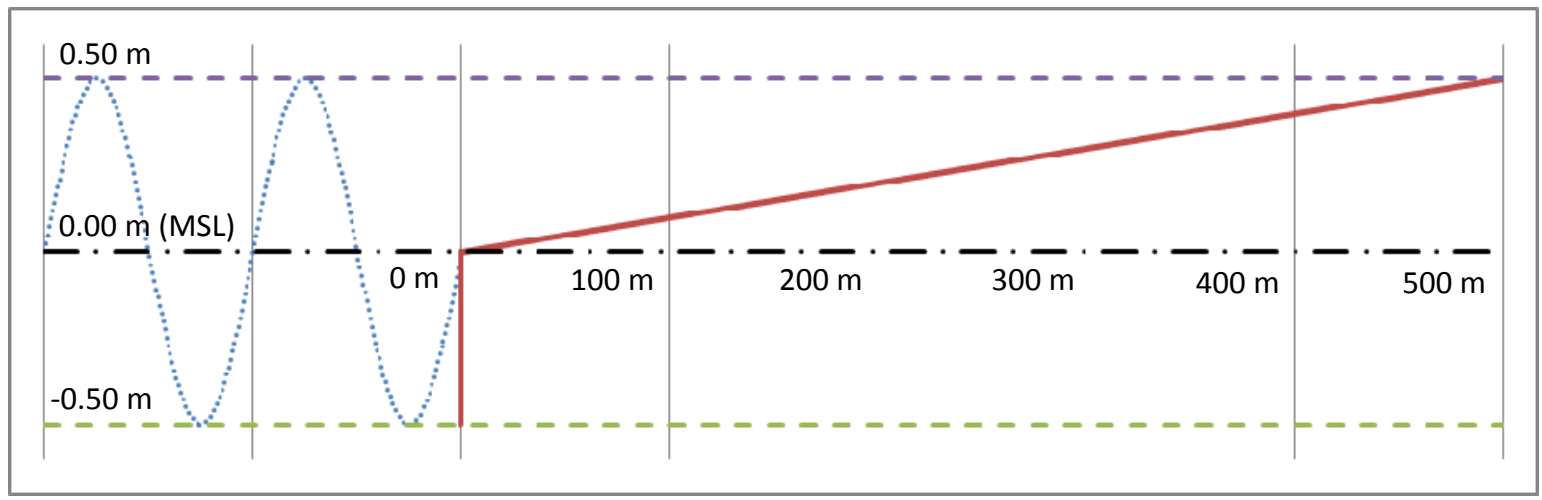

Figure 3. Side of a tidal creek with input (dotted line) and water levels.

Although flow was observed to be attenuated for $n \geq 0.2$, we only present in Figure 4 the spatial variation of flow elevation along the tidal platform for the case of $n=0.6$. Previous hydrodynamic simulations on wetlands of the Hunter estuary selected this value for vegetated areas [Rodríguez and Howe, in press]. 


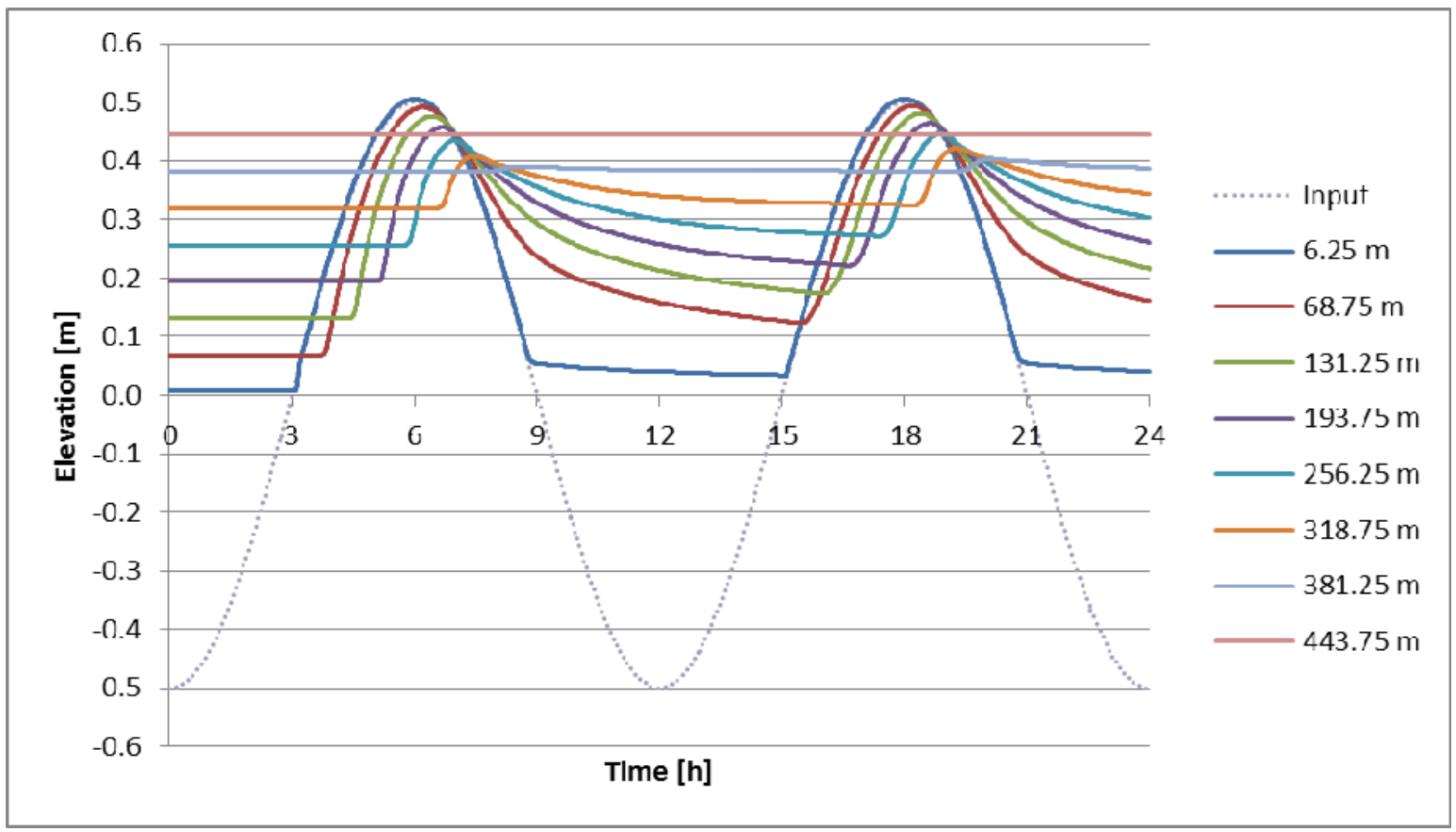

Figure 4. Tidal input (dotted line) and spatial variation of flow elevations showing attenuation $(n=0.6)$.

As we explained before, in recent years a number of numerical models have been developed in order to assess wetland dynamics using local values of depth below mean sea level. We show here that this simplification is not suitable for the cases where roughness is high. In Figures 5 and 6 we present, respectively, values of tidal range and hydroperiod along the tidal platform for several values of roughness.

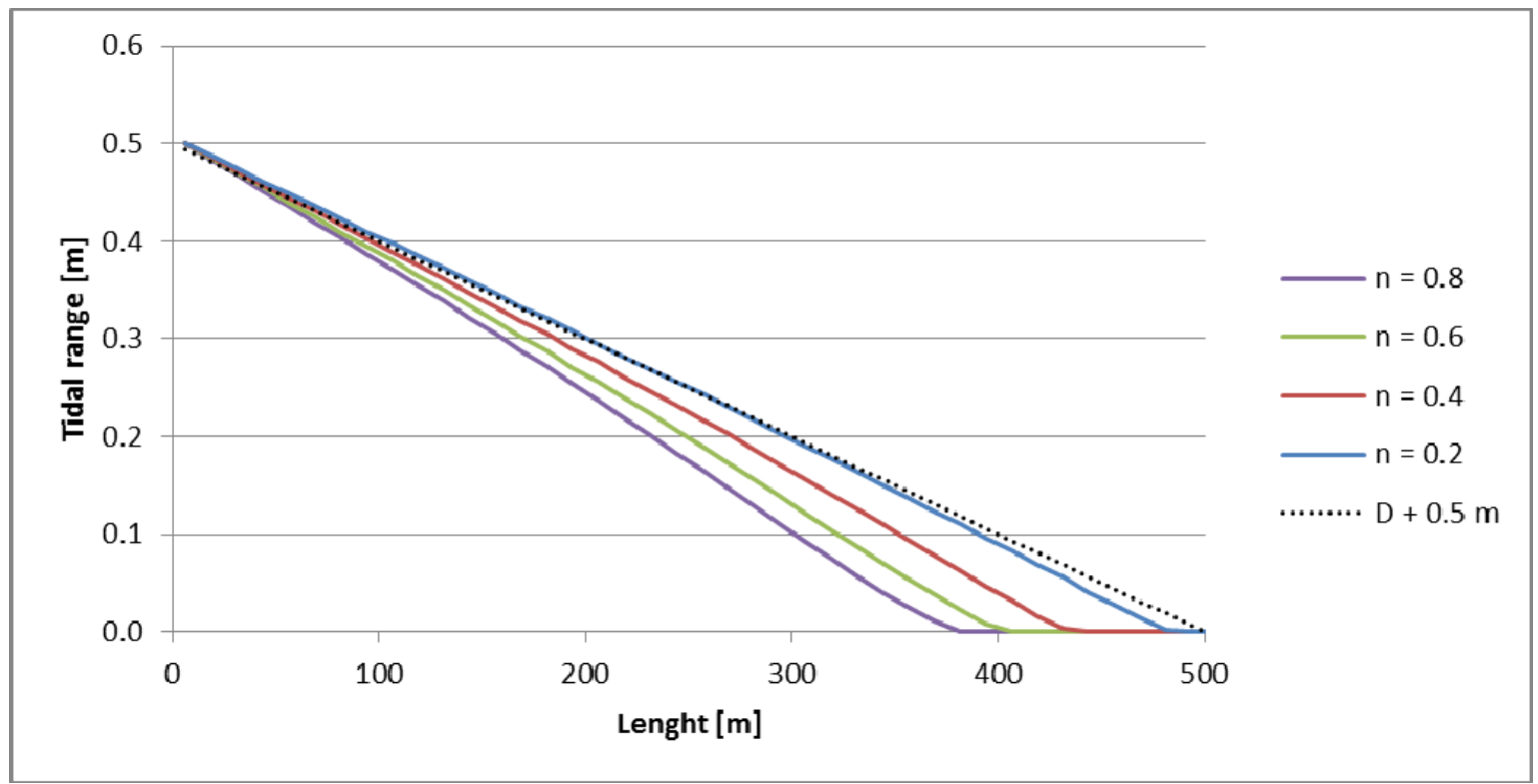

Figure 5. Tidal range $\left(R_{t}\right)$ varying with roughness and compared with depth below mean sea level $(D)$.

In Figure 5 it can be seen that a theoretical curve for tidal range $\left(R_{t}\right)$ experiencing no roughness would agree with the curve of depth below mean sea level $(D)$, with a certain vertical offset $(0.5 \mathrm{~m}$ in this case due to the position of the tidal frame). With the increase in roughness, tidal range curves move away from this theoretical curve. In Figure 6 we compare a theoretical curve for hydroperiod $(H)$ with no roughness and thus no attenuation with a curve of $D$ with an offset of $0.5 \mathrm{~m}$, as result of the combination of the position of the tidal frame and the beginning of the side of the tidal creek that we study in this case). This linear curve parallel to $D$ could be considered as a simplification used by traditional wetland dynamics models. Variations 
in $H$ due to presence of roughness are represented in this same Figure as a family of curves with an upper bound given by the theoretical curve of $H$ with no roughness.

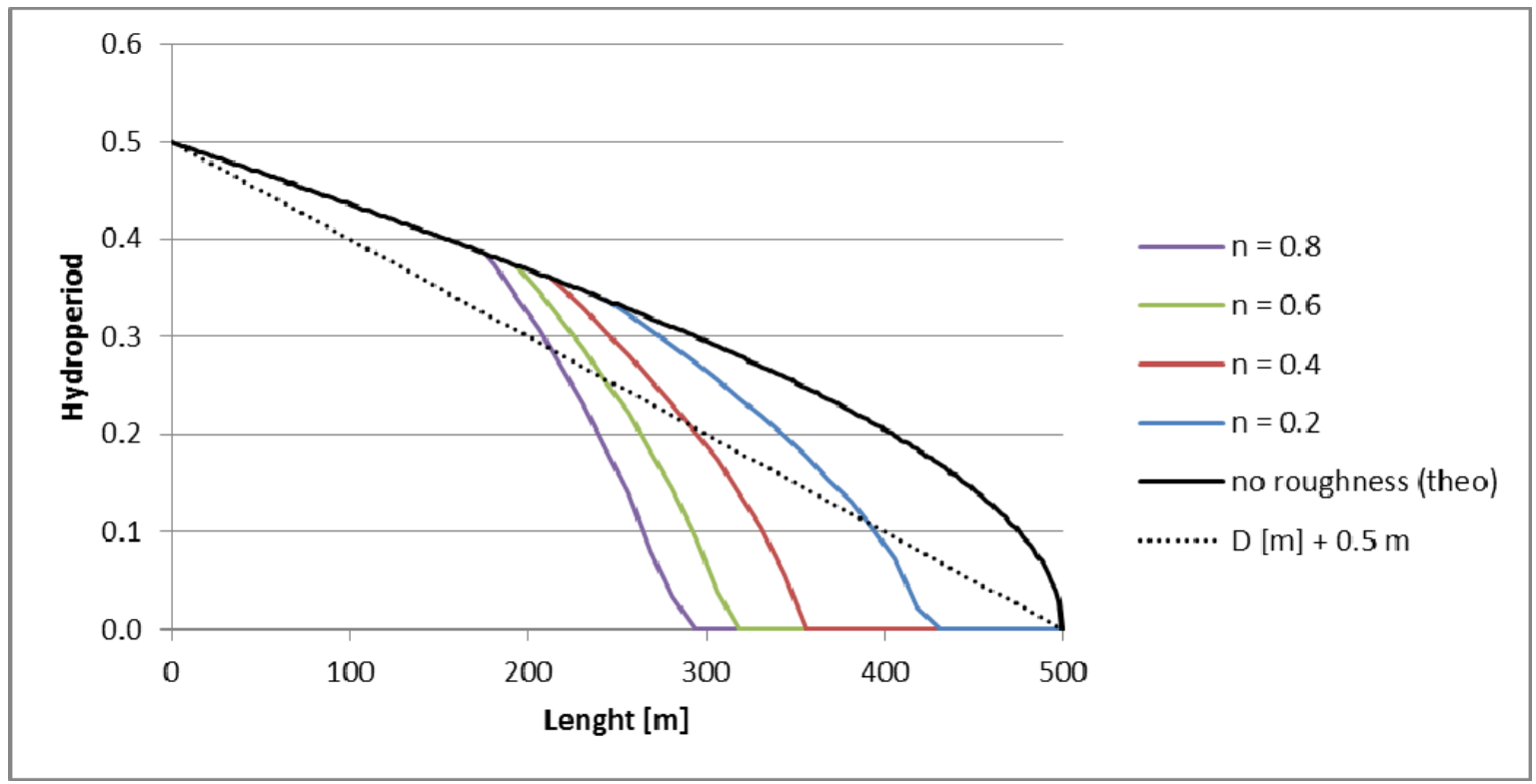

Figure 6. Hydroperiod $(H)$ varying with roughness and compared with depth below mean sea level $(D)$.

\section{CONCLUSIONS}

We have initially suggested that using local values of relative land elevation (i.e. depth below mean sea level) as the only independent variable, traditional wetland evolution models are not capable to capture the effects of flow attenuation. Two aspects of attenuation were studied with the aid of a recently developed wetland evolution model. In the first case we studied attenuation derived from man-made flow controls (e.g. culverts, weirs) with a simulation in wetlands in the Hunter estuary (NSW). Later, we analysed the effects of roughness modelling the side of a tidal creek, where vegetation is expected to occur within the wetland, considering a broad range of values for Manning's roughness coefficients $(n)$.

The first case showed the capability of capturing wetland dynamics in the presence of infrastructure and flow control structures by using spatially distributed values of the hydraulic variables hydroperiod and tidal range. Effects of man-made flow controls on temporal flow levels generate strong flow attenuation, which cannot be modelled using depth below mean sea level.

The study on a tidal platform focuses on roughness effects due to vegetation. A comparison between depth below mean sea level $(D)$ and computed tidal range $\left(R_{t}\right)$ and hydroperiod $(H)$ showed that $D$ provides a good estimate for $H$ and $R_{t}$ only for values of roughness that result in no flow attenuation. For values of $n$ greater than $0.2, R_{t}$ and $H$ have to be computed via a hydrodynamic formulation.

We have showed in this paper that local values of relative land elevation do not constitute a proxy for spatially distributed values of temporal flow elevation, as coupled values of spatially distributed tidal range and hydroperiod do. Error appears with flow attenuation. Finally, we suggest that results on wetland dynamics could be improved focusing in the representation of the vegetation module of the model. With a better understanding on vegetation preference regarding hydraulic conditions, more accurate vegetation predictions could be achieved.

\section{ACKNOWLEDGMENTS}

The first author acknowledges the financial support of the University of Newcastle through a Postgraduate Scholarship. 
Trivisonno et al., Modelling estuarine wetlands under climate change and infrastructure pressure

\section{REFERENCES}

Danone Fund for Nature (2010) Achieving Carbon Offsets through Mangroves and Other Wetlands. November 2009 Expert Workshop

Howe, A., Rodríguez, J. F. and Saco, P. M. (2009) Vertical accretion and carbon sequestration in disturbed and undisturbed estuarine wetland soils of the Hunter estuary, southeastern Australia. Estuarine Coastal and Shelf Science 84, 75-83.

Howe, A., Rodríguez, J.F., Spencer, J., MacFarlane, G. and Saintilan, N. (2010) Response of estuarine wetlands to reinstatement of tidal flow. Marine and Freshwater Research, 61: 702-713.

Mazumder, D., Saintilan, N., and Williams, R. J. (2005) Temporal variations in dish catch using pop nets in mangrove and saltmarsh flats at Towra Point, NSW, Australia. Wetlands Ecology and Management, 13: 457-467.

Mitsch, W.J., Bernal, B., Nahlik, A., Mander, Ü., Zhang, L., Anderson Christopher, J., Jørgensen, S. and Brix, H. (2012) Wetlands, carbon and climate change. Landscape Ecology, 1-15.

Riccardi, G.A. (2000) A model of cells for hydrological-hydraulic modeling. Journal of Environmental Hydrology, Vol.8, Paper 15, November 2000.

Riccardi, G., Zimmermann, E., Basile, P., Stenta, H., Scuderi, C. and Rentería, J. (2009) Rehidrología y modelo de pronósticos arroyos Ludueña y Saladillo. Informes de avance 1, 2, 3 y 4. Rosario, Argentina: Convenio FCEIAMASP, 2009, 583 pp.

Rodriguez, J.F. and Howe, A. (in press) Estuarine wetland ecohydraulics and migratory shorebird habitat restoration. Book chapter to appear in Ecohydraulics, an Integrated Approach, Maddock, I., Harby, A., Kemp, P., Wood, P. (Eds.). John Wiley and Sons, UK.

Saco P.M., and Rodríguez J.F. (2013) Modeling Ecogeomorphic Systems. In Treatise on Geomorphology, Vol 2, Quantitative Modeling of Geomorphology, Shroder John F. (Editor-in-chief), Baas, A.C.W. (Volume Editor), Academic Press San Diego, pp. 201-220.

Saintilan, N., and Rogers, K. (2006) Coastal wetland elevation trends in southeast Australia. Catchments to Coast. Society of Wetland Scientists 27 th International Conference, 42-54.

Stenta, H., Rentería, J. and Riccardi, G. (2005) Plataforma computacional para gestión de información en la simulación hidrológica-hidráulica del escurrimiento superficial. XX Congreso Nacional del Agua y III Simposio de Recursos Hídricos del Cono Sur, Mendoza, Argentina, vol. 1, CD, núm. T74, 2005, 13 pp.

Stenta, H., Riccardi, G. and Basile, P (2008) Influencia del grado de discretización espacial en la respuesta hidrológica de una cuenca de llanura mediante modelación matemática distribuida. Ingeniería Hidráulica en México. Vol. XXIII, núm. 3, julio-septiembre de 2008, pp. 123-138.

Trivisonno, F.N., Rodríguez, J.F., Riccardi, G.A. and Saco, P.M. (in press). Modelling soil, carbon and vegetation dynamics in estuarine wetlands experiencing sea-level rise. Proceedings of 2013 IAHR Congress, Tsinghua University Press, Beijing (China). 